\title{
COMPMUS: UM OBJETO DE APRENDIZAGEM PARA AUXILIAR NO DESENVOLVIMENTO DE COMPETÊNCIAS PARA O CONTEXTO TECNOLÓGICO-MUSICAL
}

\author{
Fátima Weber Rosas - NUTED/UFRGS - fwrosas@ gmail.com \\ Patricia Alejandra Behar - NUTED/UFRGS - pbehar@terra.com.br
}

\begin{abstract}
Resumo: O presente artigo apresenta o objeto de aprendizagem (OA) CompMUS e suas etapas de construção. Este tem por objetivo auxiliar no mapeamento de competências necessárias ao contexto tecnológico-musical através da composição musical digital. Para tanto, o objeto foi utilizado como um recurso digital de apoio teórico/didático em um curso de extensão ministrado na modalidade semipresencial. Entende-se que o desenvolvimento de competências para o contexto preterido é pertinente a docentes e discentes da Educação Musical ou profissionais que almejam utilizar a música como recurso em suas aulas.
\end{abstract}

Palavras-chave: objeto de aprendizagem, tecnologias digitais, educação musical

\begin{abstract}
This paper presents a learning object (LO) CompMUS and its stages of construction. This aims to assist in mapping competences necessary for the technological and musical composition through digital music. Therefore, it was used as a digital resource to support theoretical / didactic in a extension course taught in blended mode. It is understood yhat the development of competences for the deprecated context is relevant to teachers and students of music education or professionals who want to use as a resource in their classes.
\end{abstract}

Keywords: learning objects, digital technology, music education

\section{INTRODUÇÃO}

No atual contexto educacional brasileiro verifica-se uma tendência para a utilização das tecnologias digitais como recursos pedagógicos em cursos presenciais, semi e totalmente a distância. No Ensino Superior, principalmente na Educação a Distância (EAD), observa-se o uso destas tecnologias cujo objetivo é auxiliar no processo de ensino e de aprendizagem, além de tornar as aulas mais atraentes e significativas. Na Educação Musical esta realidade não é diferente. Segundo Rosas e Westermann (2009) no Brasil existiam até 2008 três cursos de Licenciatura em Música a distância no país. São eles: o da Universidade de Brasília, o da Universidade Federal de São Carlos (ambos vinculados a Universidade Aberta do Brasil), e o da Universidade Federal do Rio Grande do Sul, vinculado ao Pró-Licenciatura em Música, PROLICENMUS ${ }^{1}$. Estes cursos e também disciplinas de cursos presenciais ministradas na modalidade semipresencial, vêm utilizando diversas tecnologias digitais. Dentre 
estas tecnologias, destacam-se os objetos de aprendizagem (OAs) desenvolvidos para a EAD por equipes interdisciplinares.

Além dos OAs, softwares baseados na Web, chamados de ferramentas online vêm sendo utilizados no contexto educacional a exemplo do Google Docs. Tais recursos também se fazem presentes em cursos e disciplinas de formação de professores para atuarem na Educação Musical em suas diferentes modalidades.

Entretanto, o uso de recursos e ferramentas digitais, pois mais motivadoras que sejam não garante o sucesso do processo de ensino e aprendizagem. Conforme Behar (et al, 2009), é necessário que o professor desenvolva uma prática pedagógica consistente, fundamentada firmemente em uma ou mais teorias epistemológicas. Acredita-se que uma das possibilidades para que aconteça uma educação a distância com qualidade, é uma educação voltada para o desenvolvimento de competências.

Um processo de ensino e de aprendizagem que tem como marco de referência o desenvolvimento de competências procura conceber o aluno como um todo, em todas as suas dimensões. Neste processo, há a busca por uma articulação entre teoria e prática, formando o sujeito para situações reais ao longo da vida. Esse desenvolvimento envolve os atores participantes da EAD, professores, tutores e alunos.

Na seção 2 são descritos conceitos e termos relacionados ao desenvolvimento de conhecimentos, habilidades e atitudes, elementos necessários para o desenvolvimento de competências no contexto tecnológico-musical. Acredita-se que tais competências sejam essenciais para os sujeitos que desejam atuar na educação musical ou utilizar a música como recurso em suas aulas, tanto na modalidade presencial como a distância. $\mathrm{Na}$ seção 3, é abordado o Objeto de Aprendizagem CompMUS. Na seção 4 é apresentado um mapeamento das competências para o contexto tecnológico-musical, realizado a partir de um curso de extensão. Por fim, na seção 5, são expostas as considerações finais.

\section{COMPETÊNCIAS PARA O CONTEXTO TECNOLÓGICO-MUSICAL}

Segundo Palfrey e Gasser (2011), cada vez mais as tecnologias são utilizadas em diversas áreas do conhecimento e com diversas funções na sociedade. Os futuros profissionais necessitarão de competências para atuar num mundo cada vez mais informatizado. De acordo com Gonçalves (2012), mundialmente a EAD foi incorporada num grande número de instituições convencionais de ensino superior de maneira bimodal, ou seja, oferecendo cursos na modalidade presencial e a distância. Entende-se que as competências desenvolvidas pelos sujeitos atores (professores, tutores e alunos) da EAD são diferenciadas daquelas desenvolvidas por sujeitos atuantes na educação presencial. Contudo o uso das tecnologias digitais fazem-se presentes em ambas as modalidades que tendem a coexistir. Estudos realizados por Gonçalves (2012) apontam que a oferta de cursos bimodais parece ser uma tendência para o futuro. Desta forma, percebe-se a necessidade de cursos e disciplinas que preparem os professores para atuarem nas duas modalidades.

Através das possibilidades que a Web 2.0 oferece, todos podem criar seus próprios arquivos digitais, desde arquivos de áudio como composições musicais, acompanhamentos, trilhas sonoras até textos, vídeos, páginas web e outros para o contexto educacional.

Esta preparação dos sujeitos para atuarem no contexto tecnológico educacional envolve a capacidade para se comunicarem e se expressarem de maneira eficiente. Raposo (2012) acrescenta que o uso das TIC leva a novas formas de ler e escrever, ou seja, ao que ele chama de lectoescrita eletrônica. Nos materiais educacionais digitais ${ }^{2} \mathrm{o}$ 
conteúdo encontra-se em diversos suportes como o computador, os telefones celulares, os tocadores de mp3 digitais, etc. A principal característica destes é a leitura não linear, quase simultânea de vários textos e a possibilidade de escrita coletiva. "[...] o processo de aquisição de habilidades que permite aos sujeitos comunicarem-se e situarem-se de maneira eficiente no mundo digital." (RAPOSO, 2012, p.72). Para o autor a comunicação e expressão no meio digital implicam no domínio de competências de leitura e de escrita nesses suportes.

Ao tratarem de competência, Zabala e Arnau (2010) afirmam que esta compreende a mobilização de três principais fatores interligados, sendo eles: conhecimentos (C), habilidades $(\mathrm{H})$ e atitudes (A) formando a sigla CHA. Para os autores, o conhecimento implica em fatos, conceitos e sistemas conceituais, embora de nada adiantem se não houver a compreensão desses. A competência, portanto sugere a capacidade de reflexão e aplicação apoiada no conhecimento teórico. Para ser competente é indispensável dispor de conhecimentos juntamente com o domínio de procedimentos, ambos dirigidos por ações atitudinais.

Portanto, entende-se a competência como sendo mais do que habilidades, capacidades ou aptidões. Ela é compreendida como a mobilização desses e de outros recursos de acordo com a experiência pessoal, da formação psicológica, cognitiva e afetiva da pessoa no contexto sociocultural em que está inserida. Zabala e Arnau (2010) afirmam que a competência é:

[...] a capacidade ou a habilidade para realizar tarefas ou atuar frente a situações diversas de forma eficaz em um determinado contexto. É necessário mobilizar atitudes, habilidades e conhecimentos ao mesmo tempo e de forma inter-relacionada. (ZABALA e ARNAU, 2010, p.37).

$\mathrm{Na}$ área de Artes, em especial na Música, as tecnologias digitais também causaram impacto, possibilitando novas formas de vivenciar a música, implicando em modificações de pensamento e diferentes visões de mundo.

De acordo com a LDB 9394/96 a licenciatura plena é uma exigência na formação de docentes para atuarem na educação básica. Com a lei 11.769 a música se torna obrigatória, porém não exclusiva no ensino fundamental e médio. Neste contexto, cresce a procura pelos cursos de licenciatura, o que não poderia ser diferente na área da música.

Entretanto, conforme Ciszevski (2010) e Abreu (2011), os professores licenciados em música que atuam na educação pública básica são em quantidade ínfima. Isso se dá devido ao requisito da formação desses professores e pelo interesse em atuar em escolas de música. Com base nessas afirmações, Ciszevski (2010) menciona a importância da música nos cursos de Pedagogia, a fim de buscar uma parceria para atuar na formação musical.

Diante destas constatações, percebe-se a importância da preparação de estudantes de licenciatura em música e pedagogia para atuarem na educação musical nas duas modalidades. Entende-se que o uso pedagógico de tecnologias digitais dedicadas à música seja imprescindível em ambas modalidades. Tais tecnologias incluem ambientes virtuais de aprendizagem, recursos e ferramentas da Web 2.0 para criação, produção e composição musical, além da apreciação. É o que se denomina neste trabalho de contexto tecnológico-musical.

Quanto às competências para a música, autores como Tafuri (2008) e Hargreaves (2000) admitem a importância do contexto social, cultural e educacional no desenvolvimento das habilidades musicais. 
A pesquisadora Tafuri (2008), em seus estudos sobre a musicalidade na infância afirma que há uma predisposição para a música desde muito cedo, porém, é necessária a educação para que o indivíduo desenvolva essas habilidades. Para a autora, a maneira como o indivíduo percebe e interpreta a informação que chega ao seu cérebro depende dos conhecimentos, interesses, atitudes, personalidade, autoconfiança, temperamento, entre outros.

Segundo Hargreaves (2005), habilidades de manuseio de softwares editores de áudio para gravação e mixagem ${ }^{3}$ são essenciais para um músico na atualidade:

Ser um músico nos dias de hoje inclui algum conhecimento de improvisação e arranjo, hardware e software musical, gravação e mixagem: inclusive, pode-se argumentar que é possível compor, gravar e tocar música sem ter tido que passar muitos anos aprendendo e_praticando um instrumento. (HARGREAVES, 2005, p.04).

Para Hargreaves (2005) algumas pessoas concebem suas habilidades de diferentes formas. Algumas as consideram como fixas, isto é, que nada ou pouco pode se fazer para desenvolvê-las ou modificá-las. "[...] ou você é bom ou não é em matemática, por exemplo, de forma que muita tarefa de casa e prática não adianta muito.” (HARGREAVES, 2005, p.08). Já outras, ao invés de apresentarem um comportamento de impotência, acreditam que o trabalho pode influenciar suas habilidades.

Isto significa que independentemente de as crianças pensarem ou não que são boas em matemática, linguagem, esportes e inclusive música, o pensamento pode ser mais importante do que o grau real de suas habilidades. Isto é particularmente importante para os alunos que se acham 'não-musicais', talvez devido a um comentário desapercebido de um professor, responsável ou outro aluno, e que pode conduzir a um ciclo de 'não-tentar', e, assim tornando-o menos capaz, fazendo o tentar ainda menos, e assim por diante. (HARGREAVES, 2005, p.08).

Em concordância com as ideias de Hargreaves (2000) e Tafuri (2008), acreditase na influência do meio educacional, social e cultural no desenvolvimento de capacidades para a música. Porém, entende-se que a educação e o meio social e cultural auxiliem não somente no desenvolvimento de capacidades, mas também no desenvolvimento de competências. Tal desenvolvimento, conforme Zabala e Arnau (2010) consiste na mobilização de conhecimentos, habilidades e atitudes para um determinado contexto.

Swanwick (2003) aponta para atividades que envolvam a técnica, a execução, a composição, a literatura e a apreciação no desenvolvimento da musicalidade. Segundo ele, é preciso envolver-se com a música profundamente e não apenas escutá-la por acaso. Compreende-se a importância destas atividades para que haja um envolvimento e uma vivência musical, como também da performance no desenvolvimento das competências especializadas. Também se entende que o uso de tecnologias digitais, a exemplo do computador, não substitui a apreciação de um concerto, nem de um show ao vivo. Entretanto, com o advento destas tecnologias, acredita-se que competências para o contexto tecnológico-musical sejam necessárias para que haja uma aprendizagem mais motivadora e significativa numa sociedade cada vez mais informatizada.

Perante estas constatações, na seção a seguir apresentar-se-á o Objeto de Aprendizagem CompMUS como exemplo de recurso utilizado no mapeamento de competências para o contexto tecnológico-musical.

\section{O OBJETO DE APRENDIZAGEM CompMUS - COMPOSIÇÃO MUSICAL DIGITAL PARA A EDUCAÇÃO}


O OA Composição Musical Digital para a Educação (CompMUS) ${ }^{4}$ foi desenvolvido por uma equipe interdisciplinar da Universidade Federal do Rio Grande do Sul (UFRGS)..

Seu desenvolvimento ocorreu em quatro etapas principais, de acordo com a metodologia para construção de objetos proposta por Amante \& Morgado (2001). Estas etapas referem-se à concepção do projeto, planificação, implementação e avaliação.

(1) Concepção do Projeto: Na concepção do Projeto foram estabelecidos os conteúdos e ferramentas a serem utilizadas; os pressupostos teóricos do objeto bem como seus principais objetivos. (2) Planificação: Nesta etapa foi realizado o estudo do objeto, a construção do "storyboard" e da navegação conforme a figura 1. Foram pesquisados os tipos de recursos como mapas conceituais, mapas mentais, material complementar para a midiateca e os principais conhecimentos a serem construídos pelos alunos para a realização de composição musical digital, cuja sigla é CMD. Os vídeos, as trilhas sonoras e demais materiais também foram produzidos durante essa etapa.

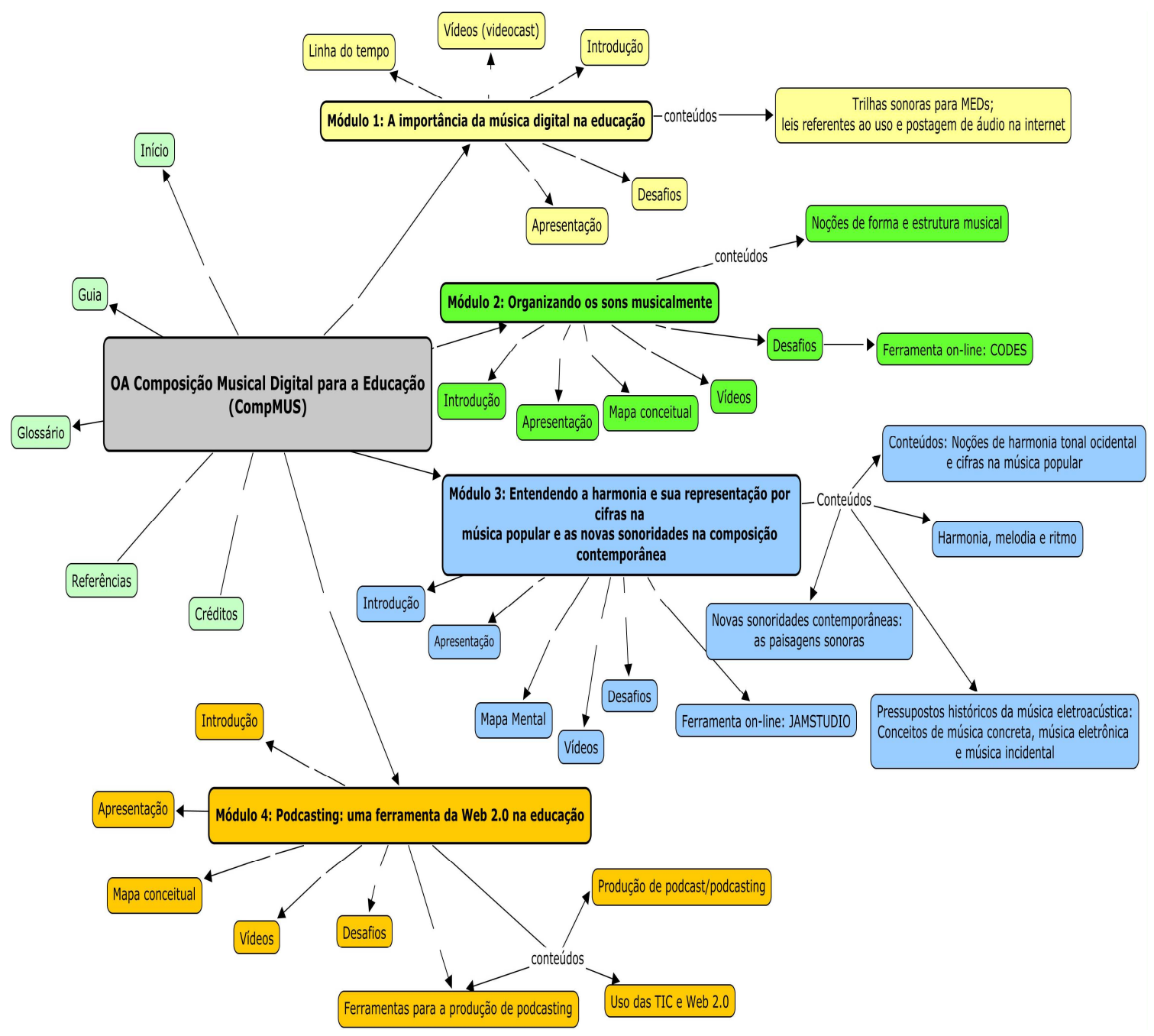

Figura 1: Storyboard do objeto de aprendizagem CompMUS.

Fonte: As autoras

3) Implementação: Nesta fase foi definido o tipo de programação utilizada bem como a construção dos primeiros protótipos. A metáfora também foi definida nesta 


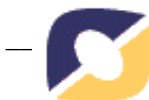

etapa. A palavra CompMUS foi escrita numa pauta com algumas letras estilizadas: letra (C) com o símbolo do compasso quaternário, letras (M) e (U) lembrando duas colcheias unidas. 4) Avaliação: Esta etapa consiste na testagem do funcionamento do objeto, seu grau de adequação ao público-alvo e o nível de cumprimento dos objetivos. Uma avaliação preliminar foi realizada através de um questionário online disponível no Google Docs após a realização de um curso de extensão com o mesmo nome do objeto: Composição Musical Digital para a Educação.

O objetivo do CompMUS é servir de recurso teórico/pedagógico no mapeamento de competências para o contexto tecnológico-musical através da apreciação e da CMD para a educação. Seus conteúdos encontram-se divididos em quatro módulos. Esse objeto possui como metáfora a imagem de um teclado musical, cujos módulos são acessados nas teclas pretas, conforme figura 2.
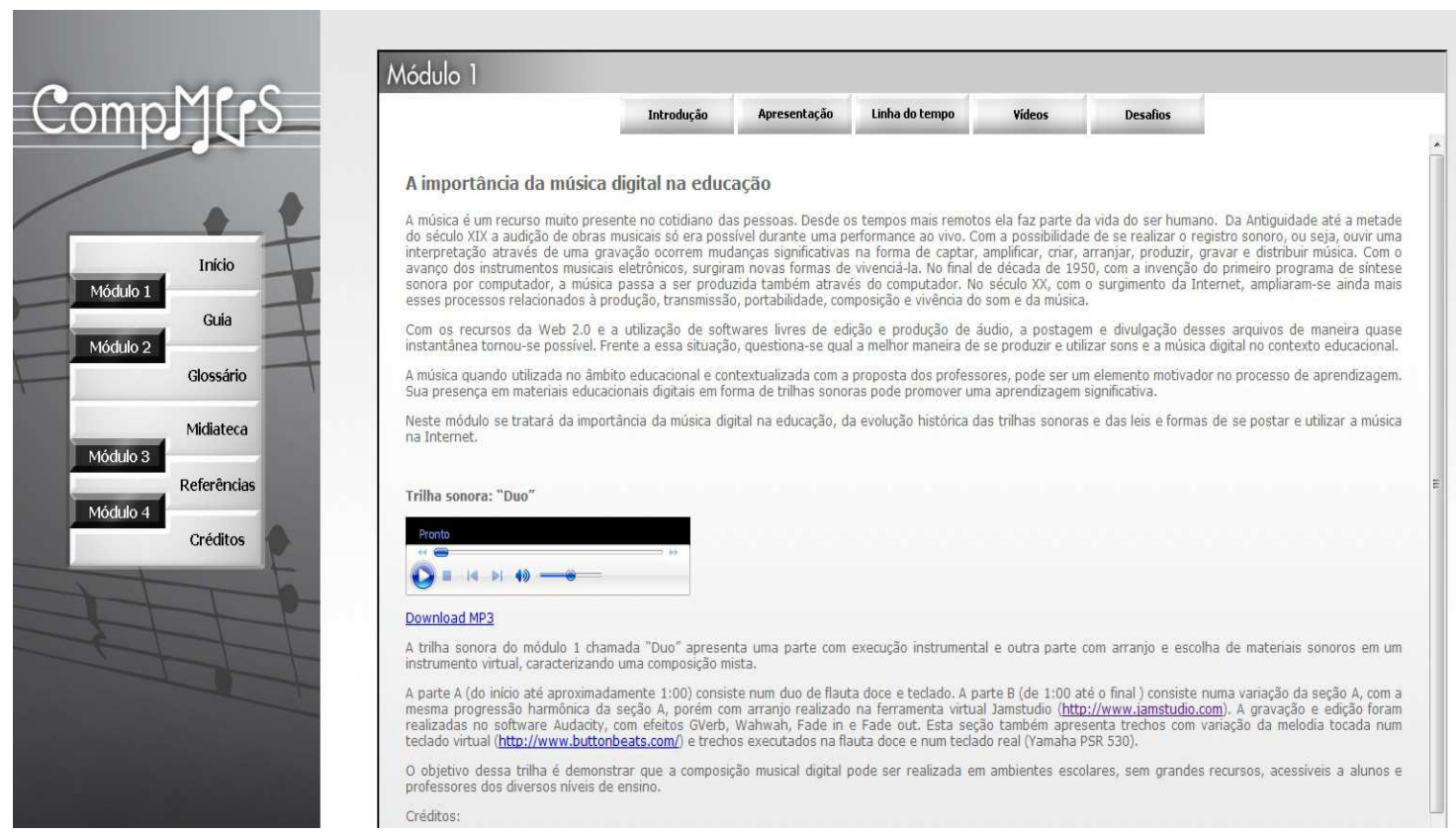

Figura 2 - Tela do módulo 1 do OA CompMUS

Fonte: As autoras

Nas teclas brancas encontram-se um texto de Início, o Guia que serve para auxiliar na navegação do objeto e possui informações técnicas para o seu uso; um Glossário contendo os principais termos e conceitos tratados; uma Midiateca com links para artigos, textos, áudios, vídeos com função de material complementar; uma lista com as Referências bibliográficas utilizadas e os Créditos.

O módulo (1) trata da importância da música digital na educação, das leis e alternativas para o licenciamento do uso de músicas na internet e da evolução e função das trilhas sonoras para o cinema, conforme figura 1. O módulo (2) aborda conteúdos voltados à forma e estruturação musical para a realização de uma composição musical. O módulo (3) apresenta pressupostos históricos da música eletroacústica, noções de harmonia tonal ocidental e de ordenamento de cifras ${ }^{5}$. E o módulo (4) trata de ferramentas da Web 2.0 e outras para a criação de podcasting. O OA possui as atividades distribuídas em seus módulos chamadas de desafios que preveem o uso de ferramentas da Web 2.0 gratuitas para a composição musical digital e para a produção de arquivos de áudio do tipo podcast. Todas as ferramentas, com exceção do Audacity 
são online, podendo ser acessadas de qualquer lugar desde que haja um computador ou dispositivo com Internet.

Os módulos 1,2 e 3 possuem trilha sonora ${ }^{6}$ composta colaborativamente pela equipe desenvolvedora através de ferramentas colaborativas online. O quarto módulo apresenta a ferramenta interativa TONEMATRIX ${ }^{7}$. Ao interagir com esta ferramenta, o usuário compõe sua própria trilha sonora para este módulo.

Este objeto deu origem ao nome de um curso de extensão e foi utilizado como apoio teórico/didático durante o mesmo.

\section{CURSO DE EXTENSAO: MAPEANDO COMPETENCIAS PARA O CONTEXTO TECNOLÓGICO-MUSICAL}

Em sua primeira edição, o curso de extensão Composição Musical Digital para a Educação foi ministrado no final de 2011, na modalidade semipresencial e totalmente a distância para alunos de fora do Estado. Seu objetivo foi mapear as competências básicas necessárias para o contexto tecnológico-musical. O público-alvo foi constituído de estudantes de licenciatura em música e em pedagogia, professores da educação básica (séries iniciais) e educação infantil, professores de música, professores do ensino superior.

O OA CompMUS foi integrado ao ambiente virtual de aprendizagem (AVA) ROODA. Foram utilizadas as funcionalidades Fórum, Webfólio, Dário de Bordo, Contatos e o ROODAPlayer ${ }^{8}$. Para mapear as competências foram utilizados estes recursos que continham todos os registros dos cursistas em relação às atividades e ao uso das tecnologias. Além destes instrumentos, foi usada a ferramenta online $\mathrm{CODES}^{9}$, que integra o desafio do módulo 2 do objeto. O JAMSTUDIO ${ }^{10}$ auxilia na criação de acompanhamentos musicais e trata-se de outra ferramenta da Web 2.0 proposta no desafio 1 do módulo 3 do objeto e que auxiliou no mapeamento proposto. Sua interface possui cifras possibilitando a criação de progressões harmônicas. Para a utilização desta tecnologia se fazem necessárias noções sobre harmonia tonal ocidental.

Portanto, a validação do objeto ocorreu através do curso citado e, a partir, deste foi possível realizar um mapeamento inicial das competências básicas para o contexto tecnológico-musical. Na tabela 1 são elencadas as competências com seus três elementos essenciais: os conhecimentos, as habilidades e as atitudes. As composições dos alunos foram realizadas através do computador. O link das ferramentas online para a composição musical digital utilizadas durante o curso também se encontram na midiateca dos módulos 2 e 3. 
Tabela 1: Competências para o contexto tecnológico-musical educacional a partir do uso de tecnologias digitais

Fonte: As autoras

\begin{tabular}{|c|c|c|}
\hline $\begin{array}{l}\text { CONHECIMENTOS } \\
\text { (C) }\end{array}$ & $\begin{array}{l}\text { HABILIDADES } \\
\text { (H) }\end{array}$ & $\begin{array}{l}\text { ATITUDES } \\
\text { (A) }\end{array}$ \\
\hline $\begin{array}{l}\text { - Conhecer diferentes formatos } \\
\text { de áudio; }\end{array}$ & $\begin{array}{l}\text { - Produzir e compor música } \\
\text { digital de maneira } \\
\text { coletiva/colaborativa; }\end{array}$ & $\begin{array}{c}\text { - Abertura a novas sonoridades } \\
\text { provindas das tecnologias } \\
\text { digitais; }\end{array}$ \\
\hline $\begin{array}{l}\text { - Conhecer efeitos para o } \\
\text { tratamento do áudio; }\end{array}$ & $\begin{array}{l}\text { - Converter formatos de áudio } \\
\text { passíveis de serem transmitidos } \\
\text { via internet; }\end{array}$ & - Autoconfiança; \\
\hline $\begin{array}{c}\text { - Conhecer pressupostos } \\
\text { históricos da música } \\
\text { eletroacústica; }\end{array}$ & $\begin{array}{l}\text { - Configurar a placa de som de } \\
\text { acordo com o sistema } \\
\text { operacional e o software } \\
\text { empregado; }\end{array}$ & $\begin{array}{l}\text { - Capacidade para motivar-se e } \\
\text { motivar os outros; }\end{array}$ \\
\hline $\begin{array}{c}\text { - Noções de forma e estruturação } \\
\text { musical para escolher e } \\
\text { organizar o material sonoro } \\
\text { disponível nas ferramentas; }\end{array}$ & $\begin{array}{c}\text { - Utilizar softwares e } \\
\text { ferramentas online, } \\
\text { principalmente as gratuitas para } \\
\text { a composição e produção } \\
\text { musical; }\end{array}$ & $\begin{array}{l}\text { - Pró-ativo (capaz de controlar a } \\
\text { estrutura e o conteúdo na } \\
\text { composição musical digital); }\end{array}$ \\
\hline $\begin{array}{l}\text { - Ler e interpertar mensagens } \\
\text { virtuais e de multimídia; }\end{array}$ & $\begin{array}{l}\text { - Utilizar softwares gratuitos } \\
\text { para gravação, edição e } \\
\text { mixagem de áudio; }\end{array}$ & $\begin{array}{l}\text { - Ter flexibilidada para } \\
\text { mudanças; }\end{array}$ \\
\hline \multirow[t]{3}{*}{$\begin{array}{l}\text { - Noções de harmonia e cifragem } \\
\text { de acordes de acordo com o } \\
\text { sistema tonal ocidental para } \\
\text { organizar o material sonoro na } \\
\text { composição musical digital; }\end{array}$} & $\begin{array}{l}\text { - Utilizar as Tecnologias de } \\
\text { Informação e Comunicação } \\
\text { (TIC) para as trocas sociais; }\end{array}$ & $\begin{array}{l}\text { - Ser responsável na utilização } \\
\text { das TIC; }\end{array}$ \\
\hline & $\begin{array}{c}\text { - Instalar e desinstalar softwares } \\
\text { musicais; }\end{array}$ & $\begin{array}{l}\text { - Saber trabalhar de forma } \\
\text { autônoma; }\end{array}$ \\
\hline & & $\begin{array}{l}\text { - Abertura a diversos idiomas } \\
\text { musicais, como o popular, o } \\
\text { erudito e o contemporâneo. }\end{array}$ \\
\hline
\end{tabular}

A partir dos resultados obtidos após o curso de extensão, foram realizadas modificações no objeto de aprendizagem a fim de aperfeiçoá-lo. Dentre elas, foi acrescentada no desafio do módulo 2 a ferramenta Remixer Club Create MusicLab, abreviado por MUSICLAB ${ }^{11}$. Semelhantemente ao CODES, essa ferramenta possibilita desenvolver um trabalho colaborativo. $O$ diferencial do MUSICLAB é que ele permite a captura de áudio externo. Desta forma, é possível tocar um instrumento e gravá-lo, armazenando o seu som.

\section{CONSIDERAÇÕES FINAIS}

O uso de tecnologias digitais como o computador, ferramentas para composição musical e objetos de aprendizagem de forma integrada, pode auxiliar no desenvolvimento de competências tecnológico-musicais no âmbito educacional. Entende-se que, além dos cursos de Licenciatura em Música, os cursos de Pedagogia devem preparar os professores para atuarem na Educação Musical, nas diversas modalidades de ensino, desde a presencial até a totalmente a distância. Para isso, necessitam de formação adequada, tanto musical quanto tecnológica. Acredita-se que 
esta capacitação teria que incluir o desenvolvimento de conhecimentos, habilidades e atitudes, elementos essenciais da competência.

Entende-se que o uso de tecnologias digitais, a exemplo do CompMUS pode auxiliar no desenvolvimento de competências. Este OA apresenta conceitos, noções, exemplos musicais e informações para manusear ferramentas da Web 2.0, proporcionando assim, situações desafiadoras para que haja a construção de conhecimentos, o desenvolvimento de habilidades e de atitudes frente a estas tecnologias.

As competências para o contexto tecnológico-musical apresentadas neste estudo fazem parte de um mapeamento inicial e abrem perspectivas para novas pesquisas a respeito do assunto.

\section{NOTAS DE TEXTO}

1- O ProLicenmus (Pró-Licenciatura em Música) é integrante do Programa Pró-Licenciaturas do MEC, sob a responsabilidade do Instituto de Artes da Universidade Federal do Rio Grande do Sul (UFRGS) e realização juntamente com Universidades parceiras. (http://prolicenmus.ufrgs.br/).

2- "[...] material educacional digital (MED), por sua vez, é todo o material educacional que aplica algum tipo de tecnologia digital na sua elaboração”. (BEHAR e TORREZZAN, 2009, p.12).

3- A mixagem faz parte do processo de produção musical onde as fontes sonoras são combinadas em um ou mais canais. Estas fontes podem ser de diferentes instrumentos, vozes, seções de orquestra, locutores ou ruídos.

4- http://www.nuted.ufrgs.br/objetos_de_aprendizagem/2011/CompMUS/. Este OA é parte integrante de um Projeto da Secretaria de Educação a Distância (SEAD) da UFRGS.

5 - Na música popular os acordes que juntos formam a harmonia, são representados por letras do alfabeto. Essas letras recebem o nome de cifras. Ex.: A letra (A) representa o acorde de (lá) maior. A letra (B) representa o acorde de (si) maior, o $(\mathrm{C})$ representa o (dó) maior, o (D) representa o ré, o $(\mathrm{E})$ representa o $(\mathrm{mi})$, o $(\mathrm{F})$ representa o (fá) e o $(\mathrm{G})$ representa o sol maior.

${ }^{6-} \mathrm{O}$ termo trilha sonora tem sido utilizado no contexto educacional por Rosas e Behar (2010) referindo-se ao uso da música em OAs.

${ }^{7-}$ http://lab.andre-michelle.com/tonematrix

${ }^{8-}$ De acordo com Behar (et al., 2011) o ROODAPlayer é um tocador de mídias digitais digitais integrado a esse ambiente.

9- COoperative Music Prototype DESign (CODES). Segundo Miletto (et al., 2005) nesta ferramenta é possível construir pequenas peças musicais chamadas de prototipações. Disponível em: http://gia.inf.ufrgs.br/CODES3/\#.

10- $\mathrm{http}: / / \mathrm{www}$.jamstudio.com

${ }^{11-}$ http://remixer.clubcreate.com/v2/musiclab/launch.html

\section{REFERÊNCIAS BIBLIOGRÁFICAS}

ABREU, Delmary Vasconcelos. Tornar-se professor de música na educação básica: um estudo a partir da narrativa de professores. Porto Alegre: UFRGS, 2011. $196 f$. Tese (Doutorado em Música). Universidade Federal do Rio Grande do Sul.

AMANTE, Lúcia. MORGADO, Lina. Metodologia de concepção e desenvolvimento de aplicações educativas: o caso dos materiais hipermídia.In: Discursos. Lisboa, Portugal. [III Série, número especial]: p. 27-44, junho. 2001.

BEHAR, Patricia A. e Col. Modelos Pedagógicos em Educação a Distância. Ed. Artmed, Porto Alegre, Brasil. 2009.

BEHAR, Patricia Alejandra e TORREZZAN, Cristina Alba. Metas do design pedagógico: um olhar na construção de materiais educacionais digitais. In.: Revista

Brasileira de Informática na Educação, Volume 17, Número 3, 2009. Disponível em: <http://www.br-ie.org/pub/index.php/rbie/article/viewFile/1023/1015>. Acesso em 11 jan. de 2011. 
BEHAR, Patricia A.; ROSAS, Fátima W. LONGHI; Magalí T. e BERNARDI, Maira. ROODAPlayer: Um tocador de mídia integrado a um ambiente virtual de aprendizagem. Revista Novas Tecnologias na Educação. V.1, nº 1, 2011. Disponível em: <http://seer.ufrgs.br/renote/article/view/21985>. Acesso em: 12 mai. de 2012.

BELLOCHIO, Cláudia Ribeiro. A educação musical nas séries iniciais do ensino fundamental: olhando e construindo junto às práticas cotidianas do professor. Porto Alegre: Universidade Federal do Rio Grande do Sul (UFRGS), 2000. 423p . Tese de Doutorado.

BRASIL. MINISTÉRIO DA CULTURA. Lei de Diretrizes e Bases (LDB) 9394 de 1996. Brasília-DF.

CISZEVSKI, Wasti Silvério. Artes e Música nos cursos de Pedagogia Paulistas. In.: I Simpósio Brasileiro de Pós-Graduandos em Música- SIMPOM. , nº I, 2010, Rio de Janeiro. Pesquisa em Música: novas conquistas e novos rumos. Rio de Janeiro. Daniel Puig Editor, 2010. p.414-422.

GONÇALVES, Maria Beatriz Ribeiro de Oliveira. A inserção da EAD em uma instituição de ensino convencional. In.: LITTO, Frederic e FORMIGA, Marcos (Org). Educação a distância: o estado da arte Vol2. São Paulo: Pearson Education do Brasil, 2012, p.294-302.

HARGREAVES, David. Within you without you: música, aprendizagem e identidade. Tradução de Beatriz Ilari. Revista eletrônica de musicologia. [online] Volume IX, Outubro de 2005. Disponível em: <http://www.rem.ufpr.br/_REM/REMv91/hargreaves.pdf> Acesso em: 21 abr. 2012.

The development of artistic and musical competence. In.: DELIEGE, Irene and SLOBODA, David. Musical Beginnings. Origins and Development of Musical Competence. Oxford: Oxford University Press. 2000. p.145-170.

MILETTO, Evandro M.; FLORES, Luciano. V.; PIMENTA, Marcelo. S.; VICARI, Rosa. M. CODES: Um Ambiente para Prototipação Musical Cooperativa Baseado na Web. In: XXV Congresso da Sociedade Brasileira de Computação - SBC. Unisinos, São Leopoldo-RS, 2005. p.1832-1846. Disponível em:

<http://www.unisinos.br/_diversos/congresso/sbc2005/_dados/anais/pdf/arq0114.pdf>. Acesso em: 15 mar. 2012.

PALFREY, John e GASSER, Urs. Nascidos na era digital: entendendo a primeira geração de nativos digitais. Tradução de Magda França Lopes. Porto Alegre: Artmed, 2011.

RAPOSO, Mariana Reis. Competência digital e a EAD. In.: LITTO, Frederic e FORMIGA, Marcos (Org). Educação a distância: o estado da arte vol2. São Paulo: Pearson Education do Brasil, 2012, pp.294-302.

ROSAS, Fátima Weber; BEHAR, Patricia Alejandra. A importância da música em objetos de aprendizagem. 2010. Trabalho apresentado no $5^{\circ}$ Congresso Latino Americano de Objetos de Aprendizagem (LACLO), São Paulo, 2010.

ROSAS, Fátima Weber; WESTERMANN, Bruno. Método de Teclado e Violão à Distância com a utilização das novas TICs. Revista Novas Tecnologias na Educação. Vol.7, №2. 2009. Disponível em: <http://seer.ufrgs.br/renote/article/view/13682> Acesso em: 19 abr. 2012. 
SWANWICK, Keith. Ensinando música musicalmente. São Paulo: Moderna, 2003.

TAFURI, Johanella. Infant Musicality. New research for educators and parents. Farnham: Ashgate Publishing Limited, 2008.

ZABALA, Antoni e ARNAU, Laia. Como aprender e ensinar competências. Tradução de Carlos Henrique Lucas Lima. Porto Alegre: Artmed, 2010. 